\title{
Noise Source Identification of Small Fan-BLDC Motor System for Refrigerators
}

\author{
Yong-Han Kim, ${ }^{1}$ Bo-Suk Yang, ${ }^{2}$ and Chang-Joon Kim ${ }^{3}$ \\ ${ }^{1}$ CRC for Integrated Engineering Asset Management, School of Engineering Systems, Queensland University of Technology, \\ 2 George Street, Brisbane, QLD 4001, Australia \\ ${ }^{2}$ School of Mechanical Engineering, Pukyong National University, Yondang-dong Nam-gu, Busan 608-739, South Korea \\ ${ }^{3}$ Digital Appliance Research Laboratory, LG Electronics Inc., Kuro 3 dong, Kuro-gu, Seoul, South Korea
}

Received 1 June 2006; Revised 4 September 2006; Accepted 6 September 2006

\begin{abstract}
Noise levels in household appliances are increasingly attracting attention from manufacturers and customers. Legislation is becoming more severe on acceptable noise levels and low noise is a major marketing point for many products. The latest trend in the refrigerator manufacturing industry is to use brushless DC (BLDC) motors instead of induction motors in order to reduce energy consumption and noise radiation. However, cogging torque from BLDC motor is an undesirable effect that prevents the smooth rotation of the rotor and results in noise. This paper presents a practical approach for identifying the source of excessive noise in the small fan-motor system for household refrigerators. The source is presumed to a mechanical resonance excited by torque ripple of the BLDC motor. By using finite element analysis, natural frequencies and mode shapes of the rotating part of the system are obtained and they are compared with experimental mode shapes obtained by electronic torsional excitation test which uses BLDC motor itself as an exciter. Two experimental validations are carried out to confirm the reduction of excessive noise.
\end{abstract}

Copyright (c) 2006 Yong-Han Kim et al. This is an open access article distributed under the Creative Commons Attribution License, which permits unrestricted use, distribution, and reproduction in any medium, provided the original work is properly cited.

\section{INTRODUCTION}

Household appliances are expected to be one of the fastestgrowing end-product markets for electronic motor drives over the next five years. The market volume for such drives is expected to increase from 19 million units in 2000 to more than 61 million units in 2006. However, the industry has desired variable-speed drives to improve its products and processes, and has understood that potentially large energy-savings and superior process control are available if adjustable-speed drives are used instead of constant-speed motors.

Currently, many appliance manufacturers are favoring the use of brushless direct-current (BLDC) motors for refrigerator and air-conditioner compressors, and circulation fan applications because of their higher efficiency, high power density, low weight, and low cost in comparison with AC induction motors or other variable-speed drives [1-3]. These motors are especially advantageous for fan applications because of their wide speed range, easy speed controllability, high efficiency, and long lifetime expectancy.

BLDC motors are disadvantageous from a vibration and noise point of view. Especially, as the speed of the motor increases and a high-energy permanent magnet is used, the exciting force of high frequency due to electromagnetic origin creates new problems. One of the electromagnetic forces that vibrate the mechanical structure of the BLDC motor is the cogging torque. Cogging torque arises from the saliency of the slot structure for winding, and depends on the magnetization pattern of the permanent magnet and the shape of the core [4]. There have been many studies about reducing the cogging torque of the permanent magnet rotor [5-8], but it cannot be avoided completely because of its electromagnetic mechanism. Sometimes, this exciting force causes resonance with the natural frequency of fan-motor systems. Accurate prediction of the natural frequencies and modes of the rotor system at the design stage is clearly critical, since an inappropriate rotor system may lead to excessive acoustic noise emissions, excessive bearing loss, and even catastrophic failure [9].

Recently, sound comfort has become more important, in addition to electric efficiency, in residential houses. The main noise sources of a household refrigerator are compressors and fans. Many companies and institutions have studied the noise reduction from a compressor, but research on fan noise has hardly been done because noise from compressors is much higher than those by fans. The general causes and the reduction plans for fan noise in refrigerators were 
TABLE 1: Design parameters of the BLDC motor.

\begin{tabular}{l|c}
\hline Design parameter & Value \\
\hline Rated voltage & $9-15 \mathrm{~V}$ \\
Rated speed & $1115-1180 \mathrm{rpm}$ \\
Fan diameter & $145 \mathrm{~mm}$ \\
\hline
\end{tabular}

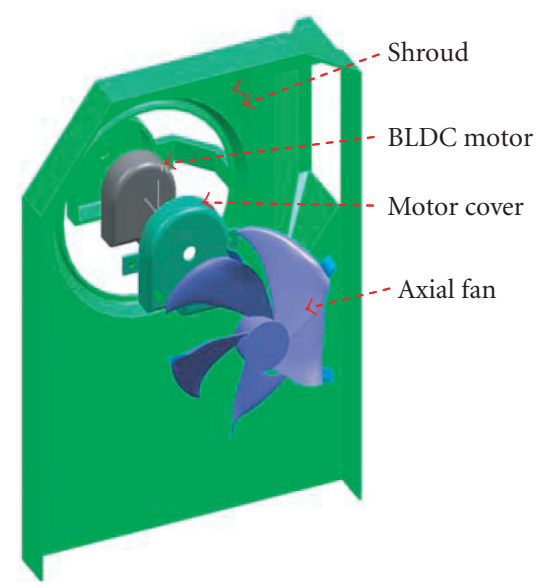

Figure 1: Schematic of an axial fan motor for refrigerators.

investigated by means of the laser Doppler velocimeter measurement, noise frequency analysis, and the search for the noise source by the sound intensity method by Takushima et al. [10].

In this paper, the excessive noise source of a fan-motor system for refrigerators is identified based on finite element analysis (FEA) and the electronic torsional excitation test (ETET). In the development stage of a new model of fanmotor system, two unexpected noise peaks were observed in the measured overall noise plot over the operational speed range. BLDC motors were adopted in this model. The most possible cause was the mechanical resonance of the shaft system which is excited by the cogging torque. IDEAS FE package [11] was used to analyze the natural frequency and mode shape of the fan-motor system. The ETET is introduced to validate the analytical mode shapes. Two experimental validations were conducted by using an altered fan and shaft.

\section{FAN-BLDC MOTOR SYSTEM}

Figure 1 shows a BLDC motor with an axial fan considered in this study. The design parameters of a prototype motor are listed in Table 1. The role of this fan is to blow the refrigerated air to a freezer chamber and a cool chamber of refrigerators as shown in Figure 2. The motor and fan constitute a single unit with two bush bearings and the shaft is inserted into the slot of the fan hub. This motor is composed of a three-phase, nine-slot winding system and a six-pole permanent magnet rotor. It is driven by rectangular voltage strokes with two phases. Figure 3 shows a block diagram of the BLDC motor drive. This motor is a permanent magnet synchronous motor with trapezoidal air-gap flux density fed by commutating

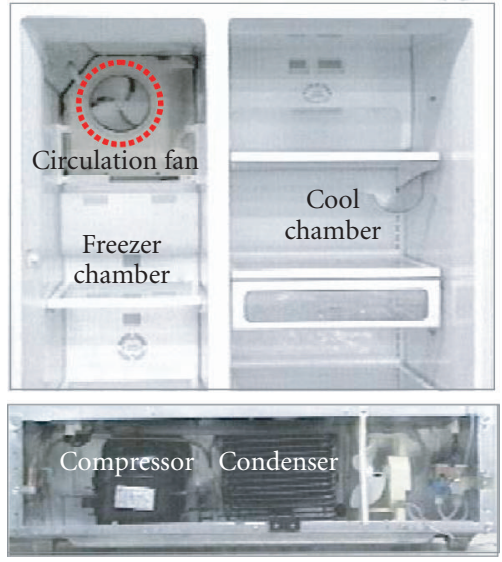

FIgURE 2: Cross section of refrigerators.
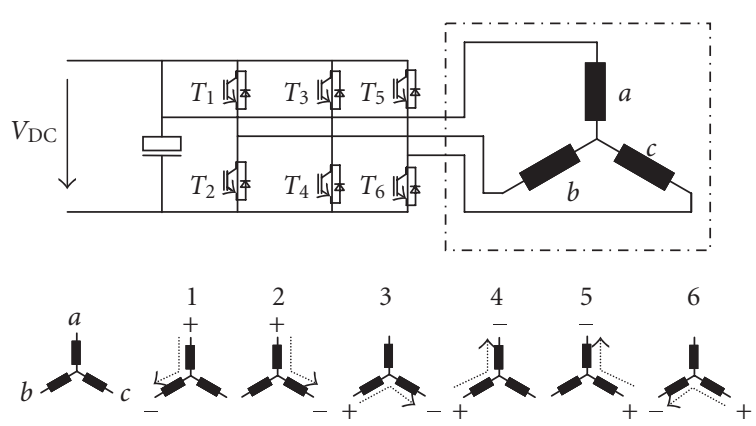

FIGURE 3: Block diagram of three-phase BLDC motor and six-step commutation sequence.

electronics. The motor runs in self-synchronous mode: the inverter output frequency is dependent on the rotor speed. Most commonly, in a three-phase BLDC motor only two phases are current-fed at the same time. For example, in step 1 , shown in Figure 3, transistors $T_{1}$ and $T_{4}$ are active. Therefore, phases $a$ and $b$ are current-fed. The voltage between terminals $a$ and $b$ is preset by the commutation electronics unit. Three digital Hall-effect sensors detect the magnetic field of the rotor. At each rotor rotation of $60^{\circ}$ electrical, one of the sensors changes its output level, alternately. At these instances, the next step of the commutation sequence is applied, and the current commutates from one phase to the next (Figure 4) [12]. Because the phase of voltage is commutated per $60^{\circ}$ electrical, the phase of current is lagged by 6 times per revolution. This current lag causes a torque ripple, which excites the fan-motor rotor system torsionally by its frequency. The ripple frequency is 18 times per shaft revolution (18X) in this BLDC motor. During the switching process, the current in each phase varies with distinctive features as shown in Figure 4. This figure illustrates the relations of switching signal, current pattern, and generation of torque ripple. 


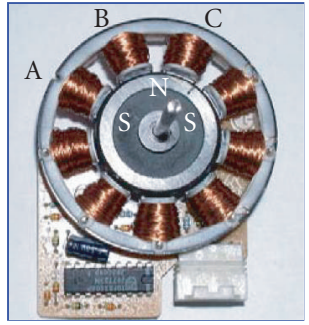

(a) Structure of the BLDC motor

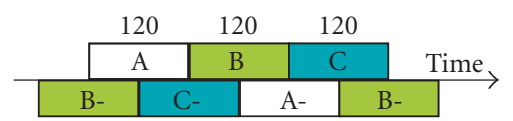

(b) Switching pattern

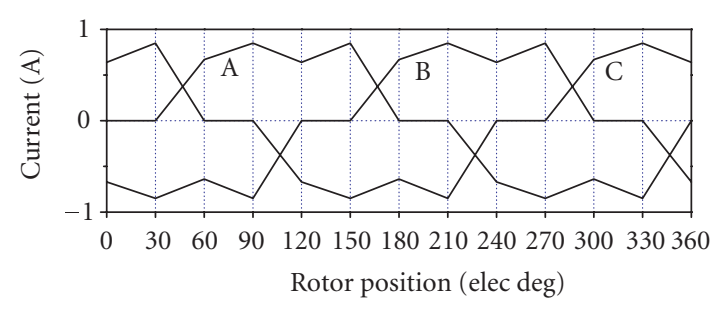

(c) Current

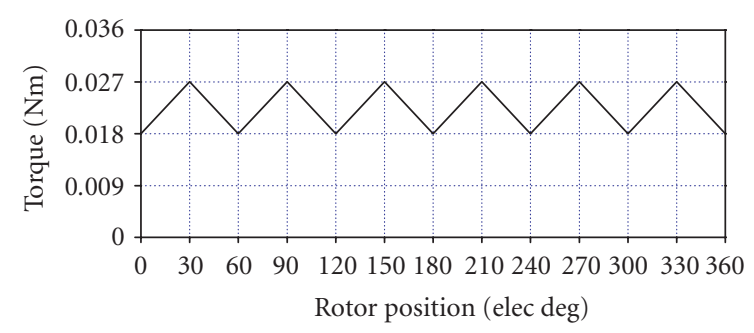

(d) Torque

FIGURE 4: Switching pattern, current and torque curves of the BLDC motor.

\section{MEASUREMENT OF NOISE AND VIBRATION}

Measurement of noise and vibration was conducted in an anechoic room. All experiments and measurements were conducted using only the fan-motor system independently detached from the refrigerator because the objective of this study was to identify causes of the unexpected high noise at certain rotating speeds, rather than to reduce overall noise level by a certain value. Three proximity probes (BN3300, Bently-Nevada) were used to measure shaft vibration and to count the rotating speed. An accelerometer (B\&K4371) was set on the top of the motor and a microphone (LA5110, Onno-Sokki) was set $0.50 \mathrm{~m}$ apart from the fan motor at the same height. A four-channel FFT analyzer (Medallion 2300, Zonic) was used for data acquisition and signal processing.

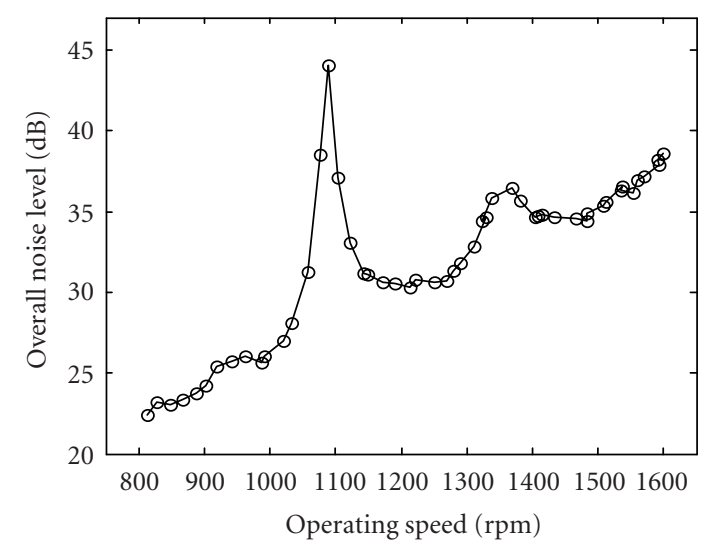

(a) Overall value

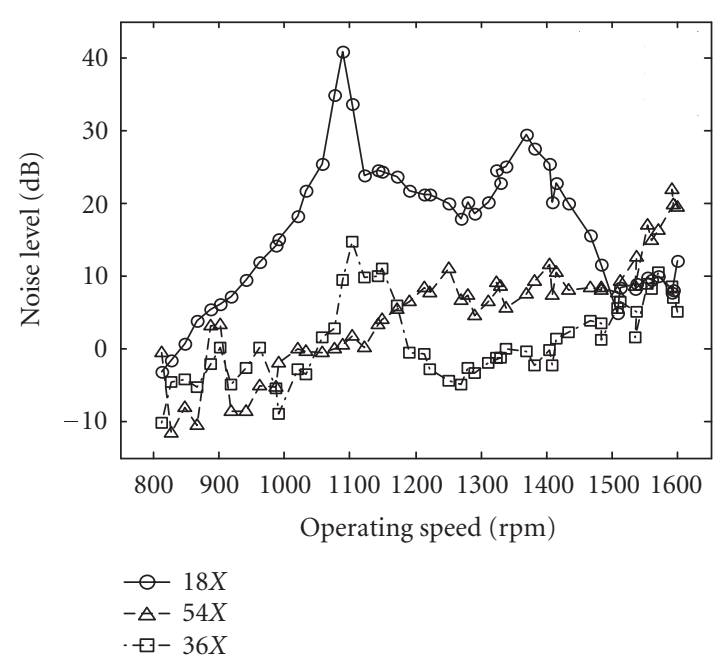

(b) Dominant spectral components

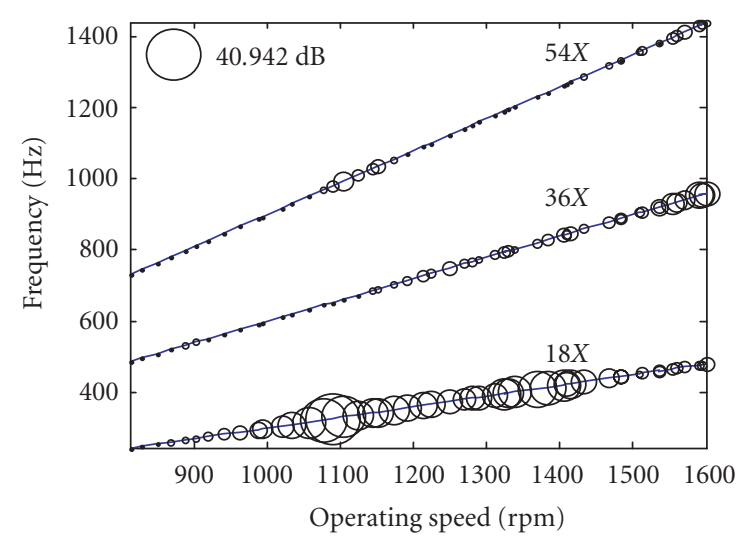

(c) Campbell diagram

FIGURE 5: Noise level of original fan-motor system.

Noise and vibration signals were acquired in the operating range from $800 \mathrm{rpm}$ to $1600 \mathrm{rpm}$.

The measured noise level of the original system is shown in Figure 5: (a) overall value, (b) dominant spectral components, (c) Campbell diagram. While, the overall value of noise shows an increasing trend as speed increases, two peaks 


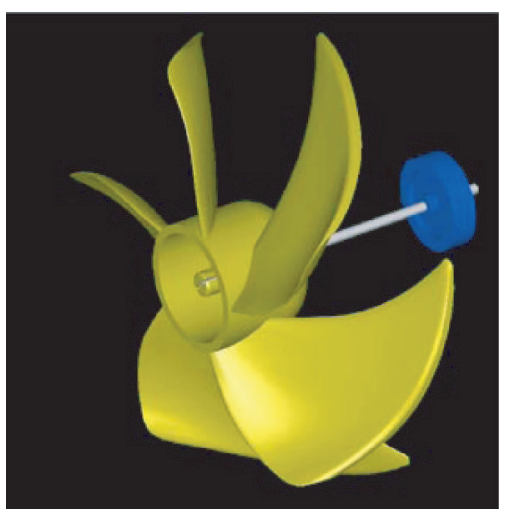

Figure 6: 3D FEA model of fan-motor shaft system.

of noise level at around $1100 \mathrm{rpm}$ and $1350 \mathrm{rpm}$ are clearly shown. These unexpected peaks of noise are the main concern of this study. As shown in Figure 5(b), the overall noise level is mostly influenced by the $18 \mathrm{X}$ (18 times of rotating speed) component which is induced by the cogging torque of the BLDC motor. Therefore, it is worth noting that reduction of the cogging torque is a primary countermeasure to reduce the overall noise. However, cogging torque itself is not a concern of this study. This paper only focuses on the identification of causes of these two peaks of noise so as to lead a modification of design of the system. The peak frequencies of $18 \mathrm{X}$ are approximately $324 \mathrm{~Hz}$ and $400 \mathrm{~Hz}$. The estimated cause of these peaks was a mechanical resonance of the rotor shaft system because the same peaks of frequency were observed in the spectrum of vibration acceleration signal.

\section{MODAL ANALYSIS USING IDEAS}

To identify natural frequencies and mode shapes of the fanmotor rotor system, three-dimensional finite element analysis (FEA) was carried out using commercial software, IDEAS (SDRC Co.). Two bush bearings support the shaft on the left and right sides of the permanent magnet rotor. As they were too flexible in the lateral direction compared to the shaft stiffness, the boundary condition was set to all free. Parabolic tetrahedron element which has 10 nodes per element was used in this study. Figure 6 shows 3D FE model for analysis. Material parameters and mesh data for FEA are listed in Table 2.

Before analyzing the whole shaft system, experiments using an electromagnetic exciter were conducted to verify the analytical model. A fan-shaft model which excludes the magnet rotor was used first. The motor-side end of the shaft was clamped on the exciter. This fan-shaft model was then excited to axial direction and five proximity probes were utilized to measure the vibration displacement at the midpoint of each blade. Table 3 shows experimental natural frequencies of the fan-shaft model compared with those by FEA. The results show that the experimental natural frequencies mostly coincide with those obtained by FEA. It is noted that the results by FEA are all slightly smaller than those by the experiment. The reason of these differences is considered to the nonlinear
TABLE 2: Material property and mesh data for FEA.

\begin{tabular}{l|c|c|c}
\hline & Fan & Shaft & Plastic magnet \\
\hline $\begin{array}{l}\text { Material } \\
\text { Mass density }\end{array}$ & ABS (HT-700) & SUS420J2 & Ferrite (Nyron6) \\
$\left(\mathrm{kg} / \mathrm{m}^{3}\right)$ & 1012 & 7800 & 3700 \\
$\begin{array}{l}\text { Young's modulus } \\
(\mathrm{GPa})\end{array}$ & 2.34 & 210 & 13 \\
Poisson ratio & 0.3 & 0.3 & 0.3 \\
\hline
\end{tabular}

- 3D solid FE element

- Parabolic tetrahedron element

- No. of node: 50,000

- Total degree of freedom: 170,000

TABLE 3: Comparison of natural frequencies by FEA with excitation test of the fan-shaft model.

\begin{tabular}{l|c|c}
\hline \multirow{2}{*}{ Mode } & \multicolumn{2}{|c}{ Natural frequency $(\mathrm{Hz})$} \\
\cline { 2 - 3 } & Measured & FEA \\
\hline 1st & 128 & 122 \\
2nd & 140 & 134 \\
3rd & 168 & 148 \\
4th & - & 235 \\
5th & 306 & 286 \\
\hline
\end{tabular}

property of the plastic fan and the connection effect between the shaft and blade.

Figure 7 shows four mode shapes of the whole fan-motor rotor system in the frequency range of interest. The $313 \mathrm{~Hz}$ mode is a in-phase fan mode as all blades move to the same direction without any deformation of the shaft. The $323 \mathrm{~Hz}$ mode is a tilting fan mode which has the first bending mode of the shaft. The $407 \mathrm{~Hz}$ mode is a typical hub mode which shows main deformations in the blade hub. The $418 \mathrm{~Hz}$ mode is the first torsional mode of shaft. In this mode, modal displacement of the magnet rotor is larger than that of the fan because of their different inertia. Among them, the $313 \mathrm{~Hz}$ and $418 \mathrm{~Hz}$ modes were suspected to the resonance frequencies which cause high-noise level when they coincide with 18 times of rotating speed. This presumption is supported by the fact that they are only the modes excited by the torsional excitation.

\section{ELECTRICAL TORSIONAL EXCITATION TEST}

A torsional excitation test was conducted to confirm the resonant natural frequencies and mode shapes. In this study, a BLDC motor itself was used as a torsional exciter by applying sine wave current to only one phase out of three phases, which is called electrical torsional excitation test (ETET). By applying sine wave current to the motor circuit using a function generator, the shaft is excited torsionally. Excitation frequency and magnitude could be easily controlled by a function generator. The vibration of fan blades was measured by five proximity probes installed slightly above each blade. The 


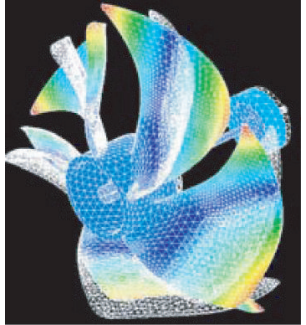

$313 \mathrm{~Hz}$

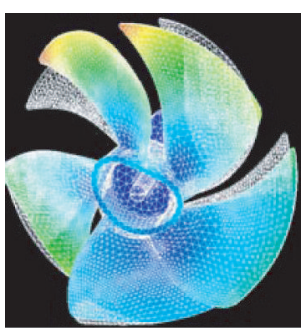

$407 \mathrm{~Hz}$

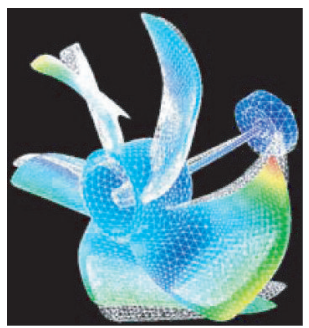

$323 \mathrm{~Hz}$

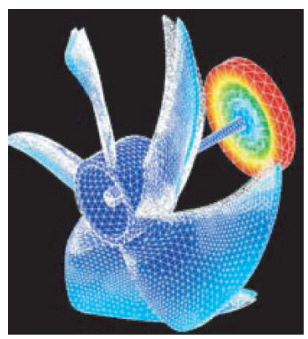

$418 \mathrm{~Hz}$
Figure 7: Mode shapes of the whole shaft system.

mode shapes were obtained from the phase and magnitude of vibration displacements measured from each blade.

By comparing and matching the natural frequencies and mode shapes obtained by ETET with those by FEA, the analytical model was verified. Table 4 shows the natural frequencies and mode shapes measured from ETET and pairing them with those from FEA. As all blades move in the same direction simultaneously, the $320 \mathrm{~Hz}$ mode from ETET corresponds to the $313 \mathrm{~Hz}$ mode from FEA. The $344 \mathrm{~Hz}$ mode from ETET corresponds to the $323 \mathrm{~Hz}$ mode from FEA because it is the only tilting fan mode. This mode is also the first bending mode of the shaft. The hub mode $(407 \mathrm{~Hz})$ from FEA was not detected in ETET because this mode cannot be excited by the torsional excitation. As the $420 \mathrm{~Hz}$ mode has in-phase movement of all blades to circumferential direction, it coincides with the torsional mode of $418 \mathrm{~Hz}$ from FEA.

As mentioned earlier, the torsional mode was assumed to one of the resonant frequencies and the analytical mode was verified through ETET. However, there is a gap of about $20 \mathrm{~Hz}$ between the peak frequency of measured noise $(400 \mathrm{~Hz})$ and torsional natural frequency by FEA $(418 \mathrm{~Hz})$ or ETET $(420 \mathrm{~Hz})$. The reason of discrepancy was clarified from a careful consideration that boundary condition of the shaft in continuous rotating operation is different with that in the torsional excitation test. When the fan is rotating to blow air forward, a reaction force always acts on the shaft in the axial direction. However, this reaction force is not active in ETET because the fan does not rotate but just vibrates delicately. In fact, since there is no bearing to get the axial force in this fan-motor system, the motor-side end of the shaft contacts with the plastic case of the motor when the shaft is rotating. There is a practical difficulty for identification of this friction force and it is not our present concern. However, we confirmed from ETET that the torsional natural frequency
$(420 \mathrm{~Hz})$ was decreased to $405 \mathrm{~Hz}$ when the shaft was set in a vertical direction so that there was an axial force by weight of fan and rotor. From the results of the FEA and ETET, it is concluded that the main peaks of overall noise were caused by resonances of which the frequencies were the $325 \mathrm{~Hz}$ and $400 \mathrm{~Hz}$, an in-phase mode of the blade, and a torsional mode of the shaft, respectively.

\section{EXPERIMENTAL VALIDATION}

Two experimental approaches were carried out to validate the conclusion from the FEA and ETET. The first trial was to change the torsional natural frequency $(418 \mathrm{~Hz})$ by shortening the shaft by $15 \mathrm{~mm}$. The second peak of the measured noise was expected to be moved to another speed. Figure 8 shows the overall noise level measured from the shortened shaft and that from the original shaft. Table 5 shows a comparison of natural frequencies for those two models. While the peak at 1,080 rpm was not changed, the peak of $1,333 \mathrm{rpm}$ which corresponds to $400 \mathrm{~Hz}$ by $18 \mathrm{X}$ excitation was disappeared in the measured speed range. Therefore, it is evident from this result that the second peak in the original noise level is caused by the resonance of torsional natural frequency of the shaft system. Furthermore, changing the torsional stiffness of the shaft can be a simple but a practical countermeasure.

Another trial was involved in changing of the natural frequency of in-phase mode $(330 \mathrm{~Hz})$. The connection part between the hub and the blade was cut by $10 \mathrm{~mm}$ in order to decrease the stiffness of the fan blade. Consequently the natural frequency of the in-phase mode was decreased. The analytical natural frequencies for the normal blade and the modified blade are compared in Table 6. Figure 9 shows a comparison of the overall noise level from the modified-blade fan with that from the original system. The highest peak near $1,080 \mathrm{rpm}$ in the original system moved to $910 \mathrm{rpm}$ in the modified fan system, and this corresponds to the natural frequency by the FEA. Therefore, this result confirms that the highest peak of noise in the original system is caused by the resonance of in-phase mode $(324 \mathrm{~Hz})$ excited by cogging torque $(18 \mathrm{X})$ of the BLDC motor. New peaks appeared in the noise level from modified-blade fan model, however, as their spectral components are extra harmonics of the cogging torque (36X and 56X), they are also related to the cogging torque. However, the highest noise level was reduced by $7 \mathrm{~dB}$. It is also confirmed by FEA that by stiffening the root part of the fan the natural frequency of in-phase mode was changed up to $357 \mathrm{~Hz}$. From a practical viewpoint, however, more attention is needed for changing the shape of blades because the efficiency of the axial flow fan is also affected by shape of the fan and it may cause another noise problem as shown in this case.

\section{CONCLUSIONS}

In this paper, a noise source of a fan-motor system for refrigerators was identified based on the finite element analysis (FEA) and the electronic torsional excitation test (ETET). 
TABle 4: Pairing of mode shapes from ETET with those from FEA.

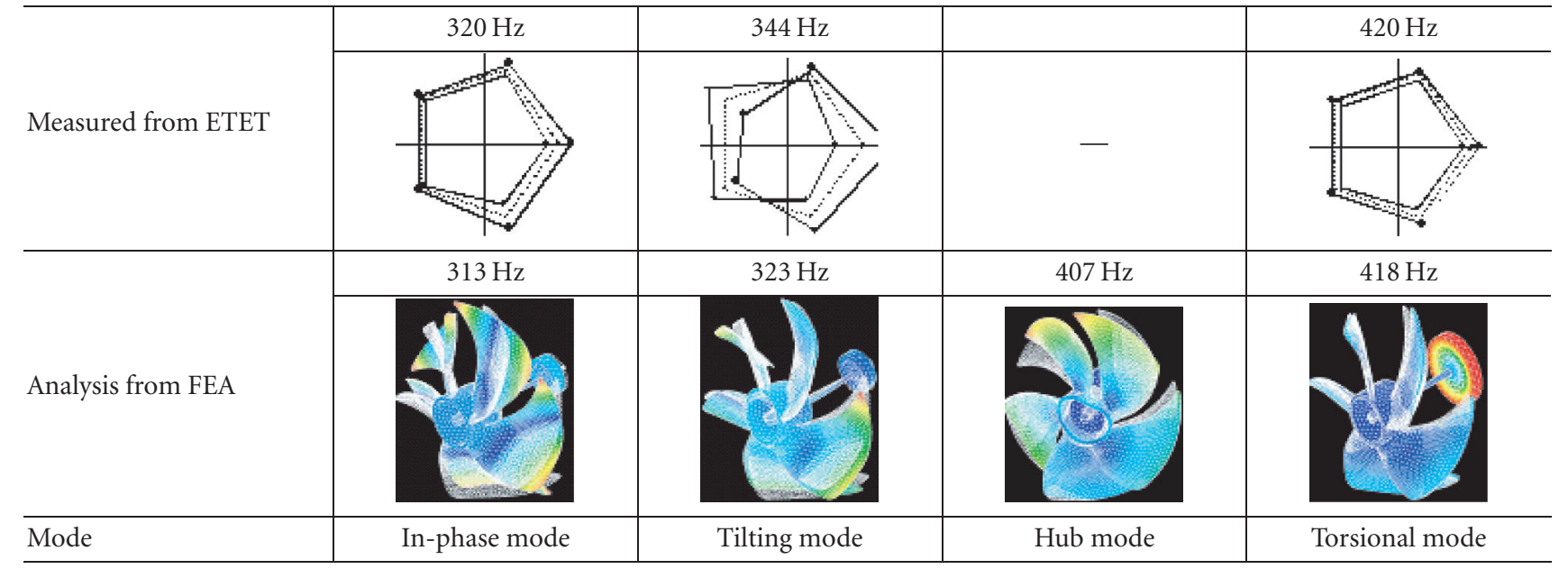

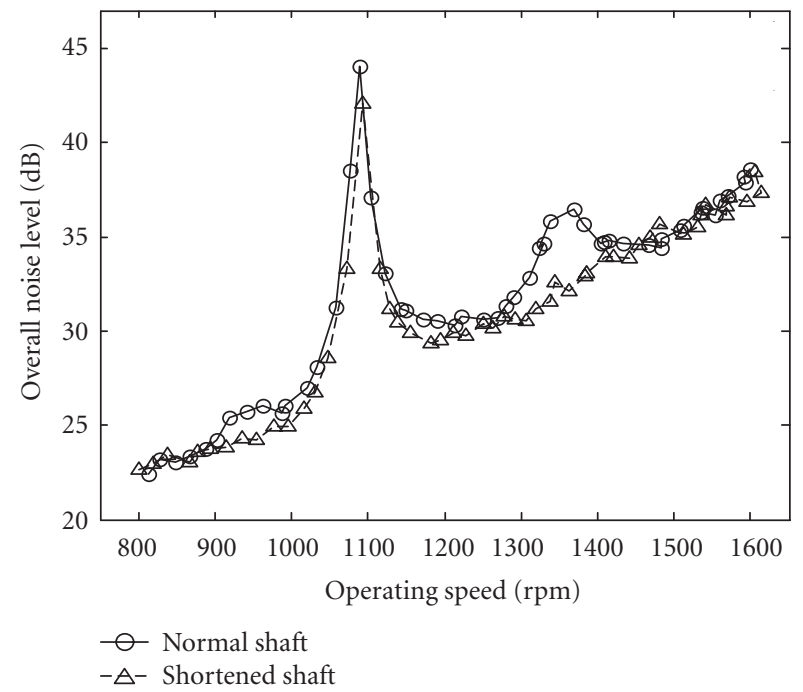

FIGURE 8: Noise level of normal shaft and shortened shaft.

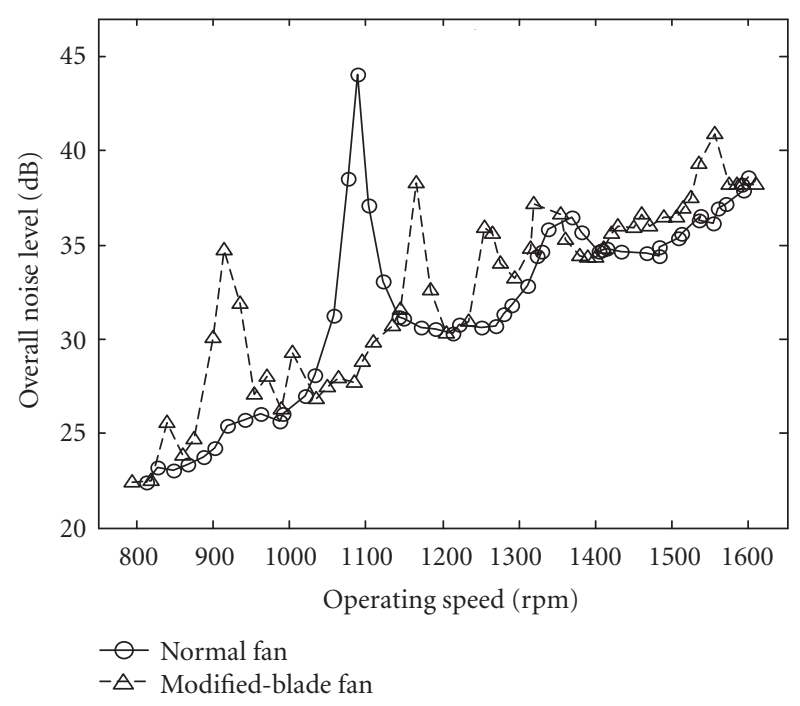

FIGURE 9: Noise level of normal fan and modified-blade fan system.
TABLE 5: Comparison of natural frequencies for normal shaft with those for shorten shaft.

\begin{tabular}{l|c|c|c|c|c}
\hline \multirow{2}{*}{} & & \multicolumn{4}{|c}{ Natural frequency } \\
\cline { 3 - 6 } & & In-phase & Tilting & Hub & Torsional \\
\hline \multirow{2}{*}{ Normal } & Measured & 320 & 344 & - & 420 \\
& FEA & 313 & 323 & 407 & 418 \\
\hline \multirow{2}{*}{$\begin{array}{l}\text { Shortened } \\
\text { shaft }\end{array}$} & Measured & 312 & 352 & - & - \\
\hline
\end{tabular}

TABLE 6: Comparison of natural frequencies for normal fan with those for modified-blade fan system.

\begin{tabular}{l|c|c|c|c|c}
\hline \multirow{2}{*}{ Model } & & \multicolumn{4}{|c}{ Natural frequency } \\
\cline { 3 - 6 } & & In-phase & Bending & Hub & Torsional \\
\hline \multirow{2}{*}{ Normal } & Measured & 320 & 344 & - & 420 \\
& FEA & 313 & 323 & 407 & 418 \\
\hline Modified & Measured & 250 & 206 & 270 & - \\
blade & FEA & 262 & 202 & 285 & 409 \\
\hline
\end{tabular}

Two peaks were detected from the overall noise level in the operating speed range measured in an anechoic room, and their main spectral component was 18 times of rotating speed (18X) which coincides with the torque ripple frequency of the BLDC motor. The commercial FEA package, IDEAS, was used to analyze the natural frequency and mode shape of the fan-motor shaft system. Four modes were found in speed range and classified into in-phase $(313 \mathrm{~Hz})$, tilting $(323 \mathrm{~Hz})$, hub $(407 \mathrm{~Hz})$, and torsional $(418 \mathrm{~Hz})$ modes. The ETET was carried out to validate these analytical results. The in-phase mode and torsional mode were presumed to the resonant frequencies excited by cogging torque of the BLDC motor, because they can be excited by the torsional excitation. This estimation was verified by comparing the peak noise measured from two modified models, shortened shaft and modified-blade fan model. In conclusion, the cogging torque of BLDC motor can cause the excessive noise 
by leading mechanical resonance of the rotor shaft system. To avoid this kind of noise problem, modal analysis using 3-dimensional finite element method has to be done in the design stage. The electronic torsional excitation test can be used effectively and simply for experimental modal test for a BLDC motor shaft.

\section{REFERENCES}

[1] I. Takahashi, T. Koganezawa, G. Su, and K. Ohyama, "A super high speed PM motor drive system by a quasi-current source inverter," IEEE Transactions on Industry Applications, vol. 30, no. 3, pp. 683-690, 1994.

[2] Z. Q. Zhu, K. Ng, and D. Howe, "Design and analysis of highspeed brushless permanent magnet motors," in Proceedings of IEE 8th International Conference on Electrical Machines and Drives (EMD '97), pp. 381-385, Cambridge, UK, September 1997.

[3] M. C. Tsai, M. H. Weng, and M. F. Hsieh, "Computer-aided design and analysis of new fan motors," IEEE Transactions on Magnetics, vol. 38, no. 5, part 2, pp. 3467-3474, 2002.

[4] H. Tajima, K. Miyashita, M. Itou, A. Tamura, and T. Konno, "Analysis of cogging torque by finite element methods," Transactions of IEE of Japan, vol. 107-D, no. 5, pp. 635-641, 1987.

[5] T. Li and G. Slemon, "Reduction of cogging torque in permanent magnet motors," IEEE Transactions on Magnetics, vol. 24, no. 6, pp. 2901-2903, 1988.

[6] M. Rizzo, A. Savini, and J. Turowski, "Influence of number of poles on the torque of DC brushless motors with auxiliary salient poles," IEEE Transactions on Magnetics, vol. 27, no. 6, part 2, pp. 5420-5422, 1991.

[7] S. Hwang and D. K. Lieu, "Characterization and reduction of reluctance torque in permanent magnet motors," in Proceedings of ASME 14th Biennial Conference on Vibration and Sound, vol. 61, pp. 217-222, Albuquerque, NM, USA, September 1993.

[8] K.-J. Han, H.-S. Cho, D.-H. Cho, and H.-K. Jung, "Optimal core shape design for cogging torque reduction of brushless DC motor using genetic algorithm," IEEE Transactions on Magnetics, vol. 36, no. 4, part 1, pp. 1927-1931, 2000.

[9] J. D. Ede, Z. Q. Zhu, and D. Howe, "Rotor resonances of highspeed permanent-magnet brushless machines," IEEE Transactions on Industry Applications, vol. 38, no. 6, pp. 1542-1548, 2002.

[10] A. Takushima, Y. Shinobu, S. Tanaka, M. Eguchi, and K. Matsuki, "Fan noise reduction of household refrigerator," IEEE Transactions on Industry Applications, vol. 28, no. 2, pp. 287292, 1992.

[11] User's Manual of IDEAS, SDRC.

[12] A. Lelkes, J. Krotsch, and R. W. De Doncker, "Low-noise external rotor BLDC motor for fan applications," in Proceedings of 37th IAS Annual Meeting and World Conference on Industrial Applications of Electrical Energy, vol. 3, pp. 2036-2042, Pittsburgh, Pa, USA, October 2002. 

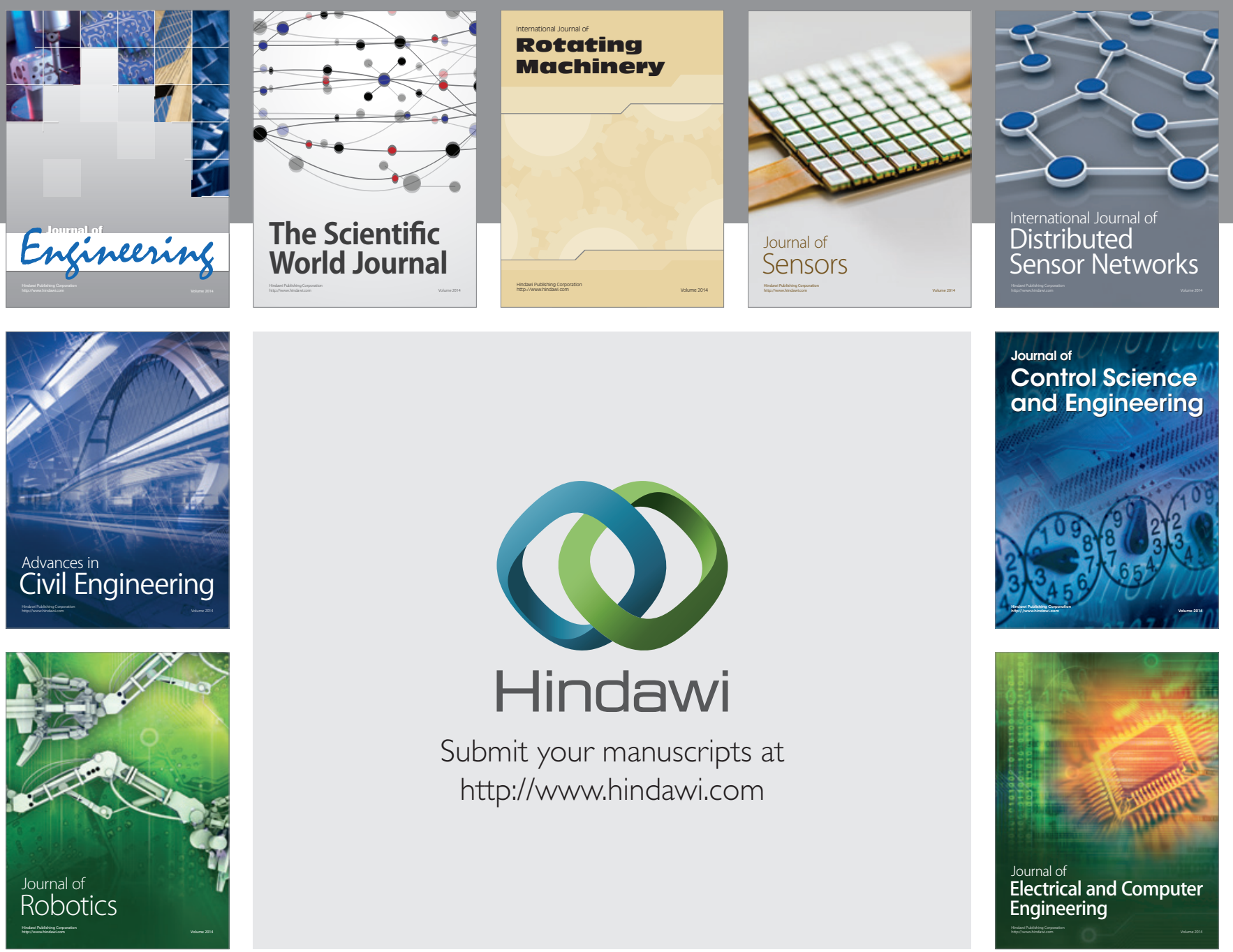

Submit your manuscripts at

http://www.hindawi.com
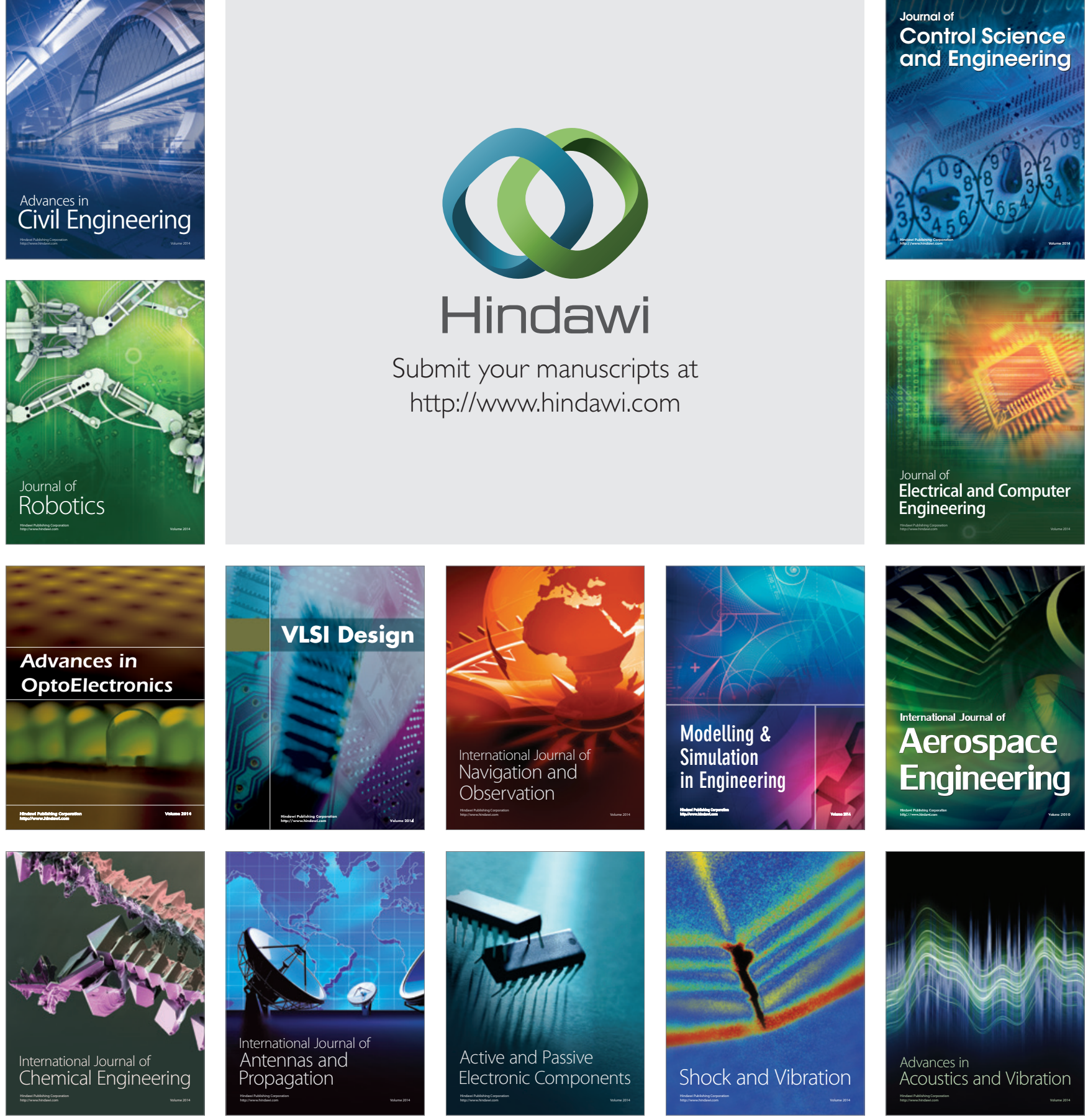